\title{
BOMBEANDO VIDA: ESTÍMULO DA CRIATIVIDADE DE PESSOAS COM DEFICIÊNCIA INTELECTUAL
}

\section{PUMPING LIFE: CREATIVITY STIMULUS OF PEOPLE WITH INTELLECTUAL DISABILITIES}

DOI: http://dx.doi.org/10.5965/1984317815022019332

Tatiellen Roberta Rogoni

Universidade Estadual de Maringá

tatyrogoni@gmail.com

Annelise Nani Fonseca

anne_nani@hotmail.com

\section{RESUMO:}

O seguinte artigo é fruto de um recorte do Trabalho de Conclusão de Curso, apresentado na Universidade Estadual de Maringá no curso de Artes Visuais em 2016. Neste objetivou-se investigar produções artísticas de modo a desenvolver propostas que estimulassem a criatividade e ampliassem o repertório artístico de pessoas com deficiência intelectual. Tal pesquisa foi desenvolvida junto aos alunos participantes de um projeto de extensão para Pessoas com Necessidades Especiais, vinculado a Universidade Estadual de Maringá (UEM). Cabe salientar que a metodologia utilizada foi a Abordagem Triangular de Ana Mae Barbosa (1998), por meio da elaboração das aulas que preconizou seus três vértices. Além disso, foi realizada a análise dos desenhos elaborados pelos alunos do projeto. A partir da análise, notou-se a ocorrência de desenhos estereotipados, em virtude disso, pensou-se na problemática: como planejar aulas de arte para pessoas com deficiência intelectual que estimulem a criatividade e ampliem o repertório artístico? Por fim, foram apresentadas as aulas planejadas a partir da metodologia descrita, que tiveram como objetivo o estímulo à criação autoral. Em nossas considerações inferimos que a mediação docente e os recursos didáticos constituem papel primordial no processo de aprendizagem de pessoas com deficiência.

Palavras-chave: Criatividade. Ensino de Arte. Deficiência intelectual. Mediação. Leitura de Imagem.

\begin{abstract}
:
The following article is the result of a clipping of the Course Conclusion Paper, presented at the State University of Maringá in the Visual Arts course in 2016. In this objective, it aimed to investigate artistic productions in order to develop proposals that stimulate creativity and broaden the artistic repertoire of people with intellectual disability. This research was developed with the students participating in the extension project for People with Special Needs linked to the State University of Maringá (UEM). It should be noted that the methodology used was the Ana Mae Barbosa Triangular Approach (1998) through the elaboration of the classes that held its three vertices. In addition, was performed the analysis of the drawings made by the project students. From the analysis, it was noted the occurrence of stereotyped drawings, because of this thought on the problem: how to plan art classes for people with intellectual disabilities that stimulate creativity and improve the artistic repertoire? Finally, the classes planned from the described methodology were presented, which aimed to stimulate the authorial creation. In our
\end{abstract}


considerations we infer that teaching mediation and teaching resources are a major role in the learning process of people with disabilities.

Keywords: Creativity. Art teaching. Intellectual Disability. Mediation. Image Reading.

\section{INTRODUÇÃO}

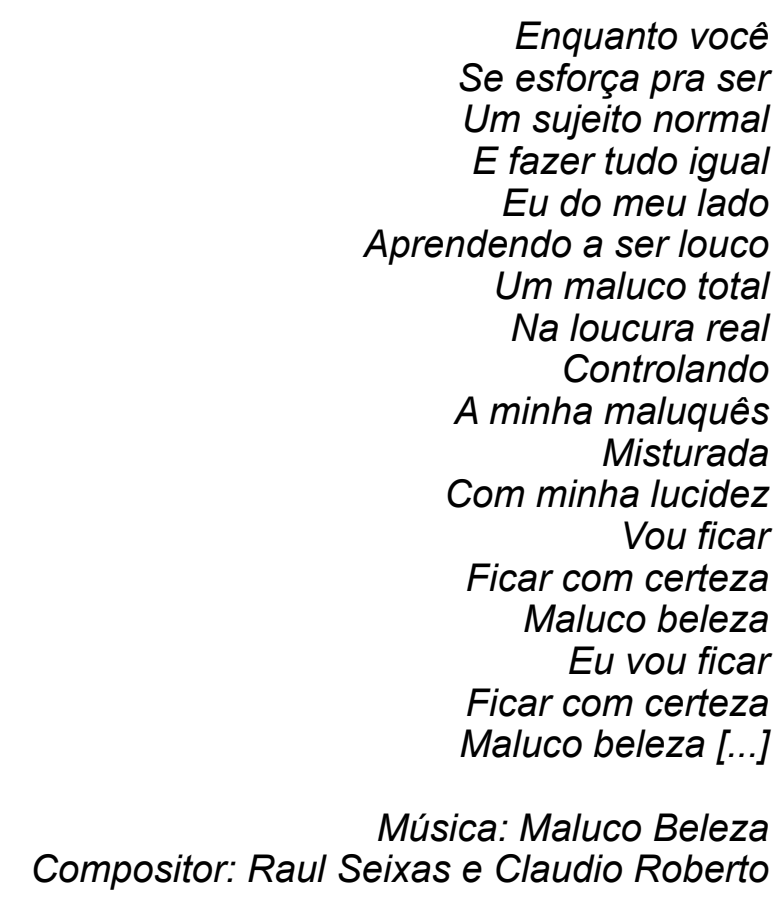

A música Maluco Beleza (1977), composta por Raul Seixas e Claudio Roberto, introduz o artigo que se segue e faz refletir sobre pontos divergentes, mas que também são consonantes na vida de um ser humano: a maluquês e a lucidez, o esforço para ser um sujeito normal e do outro lado a loucura. No trecho, "Enquanto você se esforça para ser um sujeito normal e fazer tudo igual, eu do meu lado aprendendo a ser louco, um maluco total, na loucura real”, percebe-se que é possível estabelecer conexões mais criativas que o pensamento linear. Estamos pré-ocupados com a correria e exigência de uma sociedade cada vez mais acelerada, a qual cria preconceitos que exigem a busca pela normalidade, assim como o poeta diz, pelo esforço para ser "[...] um sujeito normal, e fazer tudo igual", e esquecemos que é na diferença que nos 
encontramos e reconhecemos, ou seja, que ocorre a individuação. Neste sentido a "maluquês" é saudável em um mundo uniformizante. Diante disso, pode-se refletir a respeito de até que ponto uns são considerados loucos ou as pessoas que os julgam são reprimidas?

Vale ressaltar que a deficiência intelectual não é sinônimo de maluquice, tão quanto de loucura, essa é uma concepção do senso comum. A deficiência intelectual contém uma complexidade de transtornos psíquicos em que cada um altera funções específicas da cognição em níveis de intensidade que variam de sujeito para sujeito, e isso não significa necessariamente loucura.

As pessoas com deficiência intelectual, antes chamadas de loucas, já foram consideradas cientificamente aberrações e sem inteligência. Em virtude disso, eram marginalizadas, excluídas da educação, até colocadas em naus, encarceradas por motivos de "higienização social". Isso, por não acompanharem um processo de raciocínio instituído pela sociedade como normal, ficavam e, ainda em certas situações, encontram-se à margem da sociedade. As discussões sobre a pessoa com deficiência foram se ampliando, passando por termos como individualização, normalização, integração, até chegar nos dias atuais na discussão sobre a inclusão. Nesta perspectiva, notam-se princípios que defendem a inclusão de pessoas com deficiência, em âmbito social e educacional.

Diante do exposto, cita-se a canção Maluco Beleza de Raul Seixas e Claudio Roberto, com o cuidado de se valer da licença poética do autor para destacar algumas reflexões sobre o assunto que envolve a pesquisa - o ensino de arte para pessoas com deficiência intelectual, sem necessariamente repetir clichês e preconceitos oriundos do senso comum.

Sendo assim, as dificuldades em ensinar e aprender são circunscritas apenas quando dizem respeito a pessoas com deficiência intelectual? A partir destas reflexões e das observações nos estágios docentes, nos deparamos com a presença de formas estereotipadas nas produções de alunos considerados normais, do mesmo modo que nas produções de alunos com deficiência intelectual. Nesse sentido, o que os difere? 
As pessoas com deficiência intelectual estão aquém das consideradas normais no que diz respeito à criação artística? Perante o exposto, o objetivo deste artigo consiste em investigar produções artísticas de modo a desenvolver propostas que estimulem a criatividade de pessoas com deficiência intelectual.

Tal artigo apresenta-se como uma proposta de arte/educação pelo viés inclusivo, fundamentada a partir da abordagem triangular de Ana Mae Barbosa, na qual se propõem a pensar a aula de arte de forma a estimular a criatividade e a leitura de imagem, para que evitem a recorrência ao estereótipo. Para tanto, este trabalho de natureza teórico-prática aborda reflexões sobre a Arte/educação, criatividade e estereótipo, mediação docente, planejamento de aulas de Arte com a temática coração e análise das produções realizadas pelos participantes do projeto de extensão denominado Atividades Alternativas para Pessoas com Necessidades Especiais, vinculado à Universidade Estadual de Maringá.

Neste sentido, de forma geral, conforme Shimazaki e Mori (2012) a educação especial se desenvolveu em três momentos: Pré-Histórica, era das instituições e a época atual. Na Antiguidade existia uma postura de aceitação/tolerância e eliminação/ menosprezo a pessoas com deficiência. Foi com o cristianismo que houve aceitação dessas pessoas, mas não envolvia necessariamente uma preocupação com a educação dos mesmos. Sendo que, é somente no Renascimento que a educação para pessoas com deficiência começou a ser colocada em questão. No século XIX, na era das instituições, se apresentou uma proposta de educação especial. A partir disso, foram criadas instituições para atender pessoas com algum tipo de deficiência, porém, a criação dessas instituições fomentou o aumento da discriminação e da segregação. Enquanto que, hodiernamente se discute princípios como a integração, o atendimento especializado e a individualização na educação especial e na educação inclusiva.

Sendo assim, é preciso que os professores de Arte tenham conhecimento e contato com a heterogeneidade, tão constante entre os alunos em sala de aula. Conforme Reily (2010) o contato com alunos com deficiência permite que os professores de arte notem a importância de recursos e a necessidade de elaborar 
atividades que atendam suas demandas específicas como no campo da: "[...] linguagem, motricidade, mobilidade, acesso ao conhecimento e produção artística" (REILY, 2010, p. 86).

A temática "coração" conduziu as aulas elaboradas para o estímulo da criatividade dos alunos. Esta figura foi escolhida porque observou-se nas produções dos alunos, durante as aulas sobre emoções humanas, a recorrência do desenho do coração estereotipado. $O$ estereótipo foi apontado neste trabalho como a repetição de imagens, desenhos e ideias reproduzidos sem reflexão e desenvolvimento do conhecimento. Por fim, o coração tem função de bombear o sangue para todo o corpo, sendo assim, as propostas artísticas tiveram como intenção bombear vida, no sentido de que os alunos se desvinculassem das formas repetidas, para dar vazão à criações autorais e libertárias.

\section{ARTE/EDUCAÇÃO}

A arte/educação, antes denominada no Brasil de educação artística, foi substituída após a segunda guerra mundial (1939-1945) por apresentar problemas semânticos e conceituais na nomenclatura. De modo geral, a epistemologia da arte é o estudo do modo como as pessoas aprendem arte, desta maneira, a arte/educação deve contemplar o fazer, o ler e o ver arte. Sendo assim, o ensino de arte é imprescindível para a formação de pensamento crítico, inovador, criativo e humanizado, porque integra os âmbitos mencionados acima. Nota-se que, na conjuntura atual, se é cada vez mais bombardeado pelas imagens, o que significa que o ensino de arte se faz importante por atuar na alfabetização visual, preparando as pessoas para ler criticamente as imagens que as rodeiam. Essa leitura crítica pode ocorrer em qualquer vertente da arte, como: na televisão, cinema, obras de arte, publicidade, entre outros do campo expandido da arte.

[...] Arte é cognição, é profissão, é uma forma diferente da palavra para interpretar o mundo, a realidade, o imaginário, e é conteúdo. Como conteúdo, arte representa o melhor trabalho do ser humano. Arte é 


\section{EDUCACÃO,}

ARTE'S E INCLUSÃO

qualidade e exercita nossa habilidade de julgar e de formular significados que excedem nossa capacidade de dizer em palavras. E o limite da nossa consciência excede o limite das palavras (BARBOSA, 2014, p. 4).

Vale salientar que, conforme o excerto acima, a arte, e por consequência a arte/ educação, é um meio que estimula as habilidades do ser humano de perceber significados que estão além do uso das palavras. Além disso, conforme a autora explica, não é possível desenvolver uma educação intelectual completa, ou mesmo uma educação para elite ou popular, sem o ensino da arte.

Por meio de vivências, leituras, experimentos, mudanças de paradigmas e reflexão, são construídos e reconstruídos conceitos e ideias na sociedade. Assim o fez/faz Ana Mae Barbosa (2014) ao sistematizar a Proposta ou Abordagem Triangular, utilizada como metodologia para as aulas de arte deste artigo. A abordagem em questão preconiza o ler, o contextualizar e o fazer arte, sendo utilizada por vários professores de arte, notando-se uma intervenção qualitativa na melhoria do ensino (FERRAZ; FUSARI, 2009).

A Abordagem Triangular está envolta na luta que a autora defende, por uma educação pela arte que estimule o fazer artístico de modo integral, ou seja, a análise crítica integrada com o fazer e a leitura. A fim de se afastar da manualidade e do produtivismo (tendência tecnicista) supostamente apresentada como criativa, e da livre expressão (modo como a escola nova foi interpretada no Brasil), "[...] Ana Mae busca diversificar os focos de ensino das artes e impulsionar, mediante sua abordagem, uma articulação equilibrada entre o fazer e o conhecer" (ARRIAGA, 2014, p. 17). Tal abordagem baseia-se em ações, não necessariamente em conteúdos, por isso, pode ser trabalhada com diversos elementos e vertentes artísticas. Vale ressaltar que a contextualização que a leitura de obra de arte exige, para a abordagem, emerge dos mais diferenciados campos do conhecimento e não exclusivamente da história. Neste sentido, a contextualização pode ser histórica, filosófica, antropológica, social, 
econômica e psicológica, sendo que é o artefato artístico que impõe a eleição da metodologia de leitura (ARRIAGA, 2014).

A leitura crítica da arte desenvolve e permite a expertise nos alunos, a habilidade de ver o mundo que o cerca, a decodificação de imagens. Ela explica o lugar e tempo em que as obras estão situadas, contextos políticos e econômicos que a influenciaram. Vale salientar que a exclusividade a um único vértice da tríade, faz com que o ensino de arte seja inepto. Por exemplo, caso o professor ensine apenas o fazer sem reflexão, não se chega a uma aprendizagem significativa. Para que a aprendizagem significativa ocorra é necessário que os três pontos da abordagem triangular, o ler, o contextualizar e o fazer, estejam em sintonia, pois não há como produzir/criar sem uma reflexão crítica sobre outras imagens, sobre o seu próprio fazer e sobre o contexto que 0 envolve.

No ensino da arte deve-se preconizar propostas que adquiram "[...] oportunidade para a libertação dos desfavorecidos e se converte, por isso, em um dos elementos centrais da alfabetização cultural" (ARRIAGA, 2014, p. 21). Barbosa (2014) defende uma arte/educação para todos, independentemente da classe ou cor, para que estes tenham acesso e conhecimento do sistema de valores que fundamentam suas vidas, das normas e valores que os afetam. Assim, a arte/educação pode ser um forte instrumento de reestruturação social, quando dá acesso aos marginalizados, que sempre foram excluídos de informações, a conhecimentos políticos, sociais e históricos, conforme defende Paulo Freire, um dos pilares teóricos da abordagem triangular.

Portanto, diante do exposto, destaca-se que a arte/educação não se refere apenas ao pintar e desenhar destituído de conhecimento, conforme a crença do senso comum. Ela engloba uma gama de conteúdos que transcorrem pelo fazer, ler e ver, que justamente devido a esta integração, estimulam a expressão pela arte, e através dela exigem crítica, raciocínio, sensibilidade e criatividade que rompem com modelos alienantes, estereotipados e com a uniformização das pessoas. Por isso, a arte/ educação é um meio de conhecimento pessoal e social, de experiências significativas, 
de construção do mundo interno e externo, porque ela questiona, faz, muda, reinventa. Destaca-se, ainda, que isso justifica o seu ensino, pois ela é democrática, libertária.

\section{O ESTEREÓTIPO E A CRIATIVIDADE}

O Estágio Supervisionado é uma das disciplinas presentes em cursos de licenciatura. Especificamente, no decorrer da disciplina de Estágio Supervisionado III do curso de Artes Visuais da UEM, foi possibilitada a oportunidade de observar e experienciar na prática a teoria vista em sala, além de desenvolver aulas de arte para alunos participantes do projeto de extensão denominado Atividades Alternativas para Pessoas com Necessidades Especiais, vinculado à Universidade Estadual de Maringá (UEM). Posteriormente ao estágio, foram realizadas análises do processo de ensinar e das produções artísticas, as quais apontaram para trabalhos de alunos que seguiram a proposta apresentada durante as aulas de forma criativa, e trabalhos que se desenvolveram por meio de desenhos estereotipados, além dos que preferiram não seguir a proposta produzindo estereótipos ou não. Perante o exposto, emerge a seguinte questão: o que constituiriam desenhos estereotipados e desenhos criativos?

A palavra estereótipo, com o passar dos anos, ganhou conotações diversas e, atualmente, designa repetições de ideias, neste caso, repetições de imagens, de desenhos. São conotações que tiveram suas bases no final do século XVIII, com a invenção da estereotipia por Firmin Didot (1765-1836), um procedimento tipográfico que permitia a reprodução da mesma forma inúmeras vezes, acelerando, assim, o processo de impressão que naquela época era lento. A estereotipia fez parte da Revolução Industrial enquanto técnica de reprodução, de impressão em massa. Tal origem, em uma sociedade que valorizava a originalidade, assinalou "[...] o estereótipo com uma depreciação que finalizou por levar esta palavra ao sentido figurado negativo que se conhece hoje" (VIANNA, 2010, p. 64). Desta forma, atualmente, estereótipo tem um sentido figurado de cópia exata, de reprodução, de "fixar em uma forma invariável e perpetuar" (VIANNA, 2010, p. 64). 
Assim, entende-se que desenhos estereotipados são aqueles que se repetem constantemente de forma quase automática, sem haver variações ou combinação de outras referências. Nota-se, ainda, desenhos que apresentem elementos da cultura dominante, como por exemplo, o desenho das famosas casas com chaminés feitos por crianças brasileiras, quando no Brasil não é comum haver casas com chaminé devido ao clima tropical. Diante disso, observa-se que os professores ainda utilizam de datas comemorativas para produzirem presentes e desenhos muitas vezes estereotipados, como na páscoa ou no dia das mães.

Os desenhos estereotipados, no contexto da arte/educação, são modelos prontos que mostram como o mundo pode ser representado, com um repertório acabado e que podem ser sempre repetidos. Perante a definição de estereótipo, apresenta-se os seguintes questionamentos: como estimular a criatividade? E primeiramente, o que é ser criativo?

Sabe-se que, no senso comum, ainda persiste a ideia de que as pessoas nascem criativas ou que tal façanha seja um dom, porém, veremos adiante que a criatividade parte de variáveis internas, mas também da realidade, sendo necessário um ambiente que propicie interações, ações e estimule o potencial criador do indivíduo. Para tanto, será exposto uma breve revisão bibliográfica no que diz respeito às pesquisas em criatividade, deixando claro o aporte teórico utilizado nesta análise.

A criatividade é tema de investigações em pesquisas durante muito tempo. Segundo Ana Mae Barbosa (2008), em meados de 1960 a criatividade teve muito incentivo por conta da corrida espacial, e o resultado do incentivo à crítica e à expressão criativa foi a geração Woodstock. Depois da Guerra Fria e da força contestadora de uma geração que cresceu com estímulo à criatividade, esse tema no ensino de Artes, em modo geral, foi abafado com currículos conteudistas.

Posto isso, é importante salientar que desde a década de 1960 até a atual, foram deflagradas várias abordagens para a investigação da criatividade, por meio de inúmeros enfoques. Os autores da década de 1960 que merecem destaque são Guilford (1960) e Torrance (1962-1965), com pesquisas pioneiras que buscavam 
compreender os elementos que poderiam instigar a criatividade. A partir do campo aberto pelos pesquisadores supracitados foi possível que Walach e Kogan (1965) pudessem enveredar para pesquisas que investigassem as características da intelecção criativa, principalmente por meio do uso de testes (ALENCAR, 2003). Sendo assim, durante muito tempo, as pesquisas de criatividade foram centradas na área da psicologia. Segundo Alencar (2003) estes enfoques compreendem pesquisas em torno da pessoa criativa, a cognição criativa, o produto criativo, o contexto ambiental da criatividade, e mais recentemente fatores sociais envolvidos no reconhecimento da pessoa criativa.

Neste sentido, citaremos brevemente alguns autores de cada enfoque. Para a pessoa criativa destaca-se: Alencar (2003), que realiza um panorama geral dos autores, Sternberg (1985) e Lubart (2007) que, com a teoria do investimento e com os processos mentais envolvidos na criação, descrevem seis componentes que estariam presentes nas pessoas criativas, a saber: inteligência, estilos intelectuais, conhecimento, personalidade, motivação e contexto ambiental; e Amabile $(1983,1996)$ com o trabalho do modelo com potencial da criatividade, o qual localiza quatro atitudes vitais para estimular a criatividade: reconhecimento, encorajamento, apoio emocional, afiliação e camaradagem.

Já as pesquisas para o produto criativo enveredam para o campo do marketing, que é mais focado em fluxogramas e análise de desempenho de vendas, dentre eles destacam-se os trabalhos de Lipovestsky (2015) e Rapaille Clotaire (2007). Diferente disso, os enfoques que priorizam o contexto ambiental analisam as condições materiais para a criatividade com autores como Zorzal e Basso (2002) e Csikizentmihali (1996, 2013) que compreendem estudos acerca dos fatores ambientais que promovem a criatividade. Por meio do estado de Flow, o autor descreve a sensação de felicidade ao executar uma tarefa, sendo este o elemento presente no cotidiano das pessoas que vai configurar sua maior disposição para serem criativos. Neste sentido, o estado Flow promove a serendipity, ou seja, experiência ótima, uma capacidade de sentir prazer na realização do trabalho, perder noção do tempo e estar focado. 
No período clássico, a criação estava na perpetuação de cânones perfeitos, simétricos e tendo como princípio a beleza. Já na modernidade, conforme Vigotski (2009) expôs, a criatividade se apoiava principalmente na originalidade das formas, e os suportes utilizados continuam os mesmos (tela, argila, papel...). Já na atualidade, ou pós-modernidade, valoriza-se a elaboração e a flexibilidade na criação, os suportes mudam e abrem espaço para o hibridismo de técnicas artísticas. Segundo Barbosa (2011, p. 18), atualmente a criatividade se desenvolve nas ações de "desconstruir para reconstruir, selecionar, reelaborar, partir do conhecido e modificá-lo de acordo com o contexto e a necessidade são processos criadores, desenvolvidos pelo fazer e ver Arte [...]". Desta maneira, a base da criação está na capacidade de combinar elementos, construir o velho de novas maneiras.

Ainda de acordo com Vigotski (2009, p. 22), "[...] a atividade criadora da imaginação depende diretamente da diversidade da experiência anterior da pessoa", porque é essa experiência a base constitutiva para as construções da fantasia. Sendo assim, quanto mais experiência a pessoa tem combinada ao treinamento em comunicálas, ou seja, juntamente com aulas que ensinem a transformar experiências subjetivas em expressão plástica objetivada, maior será sua capacidade de criação.

Vigotski apresenta quatro formas de relação entre a atividade de criação e a realidade, uma delas é de caráter emocional. A emoção tem a capacidade de selecionar as imagens e ideias conforme o sentimento. Além disso, fatores cognitivos e aspectos internos de personalidade podem estimular a criatividade ou, ao contrário, inibir a pessoa como, por exemplo, quando a pessoa tem uma personalidade em que confia em si, tem coragem para enfrentar desafios e expressar ideias, perseverar diante de obstáculos, a chance de desenvolver a criatividade é maior (ALENCAR; FLEITH, 2003). Diante do exposto, observa-se que a criação é movida tanto por sentimentos, personalidade, pensamentos, quanto pela interação com o ambiente, e depende sempre de experiências vividas e adquiridas.

Além das pesquisas supracitadas, as mais recentes envolvem os fatores sociais envolvidos no reconhecimento do trabalho criativo, se debruçando para fatores antes 
não mencionados, como questões de gênero e de colonialidade. Com relação a de colonialidade, segundo Victor Kon (2019), Ramón Cabrera (2019), Nora Merlín (2019) e Achinte (2019), a colonização ainda é presente inconscientemente, visto que ele interfere nos juízos de valor em realização a própria cultura, visto que ela implementou um processo de desvalorização da cultura local por meio da hipervalorizarão da cultura europeia, que faz com que a capacidade propositiva e, por sua vez, a criatividade, fiquem prejudicadas. Neste sentido, em pessoas de países colonizados, um sentimento de atraso e inadequação é constante, visto que as coisas consideradas criativas eram as da colônia.

Além disso, as contribuições dos estudos feministas e do movimento negro também salientam que gênero e raça são elementos que interferem diretamente no que é considerado criativo, dentre eles destaca-se Loponte (2008) e Ning Luo (2019), afirmando que o mito do "gênio criativo" ser homem, além da cultura do patriarcado, afeta que as produções feitas por mulheres tenham mais dificuldade de serem reconhecidas como criativas, o mesmo ocorre com as produções feitas por negros em virtude do racismo, conforme afirma Vanessa Souza (2017).

Perante o exposto, pode-se inferir que além dos fatores cognitivos e a personalidade criativa, existe uma miríade de influências que devem ser consideradas ao analisar a produção criativa, portanto, quando se volta para o recorte desta pesquisa, o trabalho criativo realizado por pessoas com deficiência intelectual, adiciona-se mais uma camada de preconceito no julgamento, ou na falta dele, dessas produções. Neste sentido, o trabalho das pessoas com deficiência intelectual passa por mudanças de paradigmas, visto que ele também pode contemplar os novos enfoques metodológicos citados.

Durante muito tempo, nas abordagens mais centradas na estrutura de personalidade da pessoa criativa e na cognição criativa, o trabalho realizado por pessoas com deficiência intelectual não era tão comumente mencionado em virtude do preconceito com relação à sua capacidade cognitiva. Quando estas pesquisas se expandem para observar os aspectos ambientais e sociais, elas permitem que a 
análise do trabalho de pessoas com deficiência intelectual seja observada para além da deficiência e da esfera da terapia ocupacional. Assim, os trabalhos podem ser analisados a partir de como eles são afetados por questões de gênero, de raça, da colonização, do mercado, que não são mencionados na grande maioria das pesquisas e certamente merece futuros estudos.

Outra questão deve ser tratada nesta seção para esclarecimento das análises feitas nas produções artísticas dos alunos. Dito isso, podemos nos interrogar, após uma aula prática que estimule a criatividade dos alunos, como julgar o trabalho como criativo? O que faz ser criativo ou não? Conforme Amabile, apud Alencar e Fleith (2003), algo é considerado criativo na medida em que é novo e se faz útil ou tem valor para a tarefa em questão. Ou seja, quanto mais adequada for a resposta para o que se procura, mais criativo se faz.

Além disso, entender o trabalho do aluno como criativo ou não, depende também dos critérios e objetivos elencados pelo professor. Para alcançar bons processos e resultados, faz-se importante que o professor compartilhe com os alunos quais os critérios que permearão a produção destes, além de analisar em sala como outros artistas apresentaram soluções criativas para as temáticas discutidas. Sendo assim, em primeiro lugar, o professor precisa planejar sua aula, juntamente com os objetivos da mesma, para que posteriormente tenha meios para analisá-la e perceber se a mediação realizada permitiu que os alunos ampliassem o repertório artístico e a criatividade. Destaca-se que, além de cumprir com a proposta do professor, é importante que os alunos vinculem o que foi analisado em sala com sua subjetividade, suas preferências, seu enquadre, sua perspectiva do assunto estudado.

Perante o exposto, pode-se inferir que todos os componentes citados, intrínsecos, como as características pessoais; e extrínsecos, como fatores do contexto sociocultural e a complexa interação entre eles, influenciam no processo criativo e podem instigar o aluno a romper com estilos e ideias empregados habitualmente $e$ desenvolver imagens mais criativas, conectadas com o que ele pensa e sente, ou seja, apresenta criações com uma linguagem autoral. 


\section{MEDIAÇÃO DOCENTE}

Por meio do que foi apresentado, fez-se necessário o aprofundamento sobre como a mediação docente se constitui nas propostas artísticas, para no próximo título apresentar as aulas elaboradas, tendo como referência os estudos sobre a criatividade e a mediação docente.

Uma mediação em arte se forma na articulação entre o conhecimento pessoal e coletivo, enredada nas referências sócio-histórico-cultural da humanidade. Infere-se, assim, que o ensino de arte na contemporaneidade veio sofrendo mudanças, pois, o ensino que era voltado ao desenvolvimento das habilidades artísticas, atualmente vem abrindo caminhos para um ensino articulado em que a arte é trabalhada e considerada como expressão, conhecimento, crítica e cultura, com suas vinculações sociais, políticas e econômicas (COUTINHO, 2009). Perspectiva esta que pode ser alcançada pelo referencial teórico utilizado neste trabalho, a abordagem triangular.

Neste contexto, o professor de Arte ou o arte/educador pode compreender o ensino como mera reprodução de informações e modelos já estabelecidos, porém, no processo de mediação docente é preciso que o professor passe de sujeito passivo para sujeito ativo, já que a mediação consiste na interação e na apropriação dos conhecimentos (COUTINHO, 2009), em que o professor mediador se coloca entre o significado cultural e as melhores formas de apropriação deste pelos alunos. Além de ser meios que contribuem para a permanência, transformação, renovação dos modos de olhar, fazer e interpretar.

O mediador promove o diálogo entre a imagem e o aluno, "[...] instaura laços, levanta hipóteses, integrando diversos olhares na perspectiva de uma interpretação plausível" (AZEVEDO, 2009, p. 337). O professor/mediador cria um sistema de trocas de informações e interpretações, a fim de que o aluno compreenda a dimensão estética e artística presente no cotidiano e tenha condições de criar sua própria interpretação, além de ser um veículo para que o aluno reflita e questione sobre a sociedade em que 
vive. Nesse caminho, o arte-educador também precisa exercer sua capacidade reflexiva e crítica, tomando a posição de um educador pesquisador e mediador, pois, enfrentará durante sua atuação grandes desafios e não poderá perder de vista sua própria formação continuada.

Conforme Tourinho (2009) a percepção do aluno pode ser a mais singular possível, porém ela sempre é construída por visões e elementos do grupo social com o qual convive. Desta maneira, nota-se que as referências e interações feitas pelo professor, junto à cultura visual do aluno, são formas que podem ser entrelaçadas, a fim de construir significados para o próprio aluno, gerar reflexões e criações mais enriquecidas, subjetivas e críticas. Salienta-se que a mediação docente se faz importante quando o professor apresenta ao aluno diversas referências e signos produzidos pela humanidade, estes signos culturais são internalizados aos poucos pelos alunos.

Segundo Garcia (2012, p. 71), Vygotsky defende que "[...] as leis gerais do desenvolvimento são iguais para todas as crianças", ou seja, o desenvolvimento de uma criança considerada normal e de uma com deficiência, de modo geral, ocorrem da mesma forma. Entretanto, é necessário compreender as especificidades de cada aluno e organizar caminhos diversos e recursos didáticos que atendam à organização sociopsicológica do aluno em específico. Portanto, o grupo de pessoas com os quais o aluno tem contato (família, amigos, professores) deve oferecer referências e estímulos concretos para que tenha condições de se desenvolver e aprender. Sendo assim, o indivíduo deve ter o direito de participar de ambientes sociais diversificados para que tenha acesso de fato aos ensinamentos culturais.

Desta forma, a mediação cultural apresenta suma importância para a interação social e construção do indivíduo, destacando que esta implica em trocas de conhecimento e diálogo com o professor e com o outro, e ampliação de repertório pessoal e cultural. Neste sentido, ao utilizar caminhos e recursos variados é que se pode alcançar meios para proporcionar o ensino para pessoas com deficiência intelectual. Os recursos didáticos devem ser elaborados a partir dos mesmos 
pressupostos necessários para o desenvolvimento dos demais. Desta forma, as características discutidas vão contribuir para configurar um desempenho específico de cada aluno independentemente da existência de deficiência ou não.

Por fim, a mediação docente como meio para a aprendizagem e desenvolvimento das potencialidades dos alunos torna-se indispensável. O professor deve elaborar os materiais apropriados aos alunos e com eles mediar a formação de conceitos, o desenvolvimento das funções psicológicas superiores, para então proporcionar a interação social, a apropriação da cultura e o aprimoramento dos níveis de pensamento (GARCIA, 2012).

\section{PROPOSTA ARTÍSTICA: UM CORAÇÃO CRIATIVO}

A proposta artística apresentada na sequência foi realizada pelos alunos participantes do projeto de extensão denominado Atividade alternativa para pessoas com necessidades especiais (aproximadamente 8 alunos) vinculado à Diretoria de Extensão (DEX), Departamento de Teoria e Prática da Educação (DTP) e ao curso de Pedagogia da Universidade Estadual de Maringá (UEM), coordenado pela professora de pedagogia Gizeli Alencar. Pontua-se que os alunos já estavam diagnosticados pelo projeto como pessoas com deficiência intelectual e, especificamente, além da deficiência intelectual, alguns alunos apresentavam outro tipo de deficiência ou doença, como paralisia cerebral, síndrome de Down e esquizofrenia. Os alunos já tinham intimidade entre si e com os estagiários, que durante todo o ano realizavam projetos. Por ser um grupo bastante heterogêneo, a convivência e amizade facilitou uma mediação cultural rica em referências, discussões e afetos junto às diversidades. Fazse necessário ressaltar que foi realizado o Processo de Consentimento Livre e Esclarecido com os responsáveis e alunos para possibilitar a publicação e análises das produções que se seguem, valendo-se do cuidado para não identificar o nome dos alunos. 
Embasado nas discussões apontadas até aqui, foi planejado aulas de Arte que estimulassem a criatividade de pessoas com deficiência intelectual, partindo do contexto social ali encontrado. Após ter refletido sobre as produções dos alunos durante o estágio em Arte, averiguou-se uma considerável produção da figura do coração estereotipada e achou-se relevante a elaboração de aulas de arte com tal temática, um órgão muscular, que bombeia sangue através de veias e artérias para o corpo, e, principalmente, por ser considerado o centro vital das emoções e sensibilidades do ser humano.

Vale ressaltar, que a produção estereotipada não é exclusividade nas produções artísticas de alunos com deficiência intelectual, pelo contrário, isso atesta sua inserção na cultura tal qual como se apresenta em alunos sem a presença da deficiência. Perante o exposto, sentiu-se a necessidade de preparar aulas que discutissem a estereotipia na produção plástica.

A aula elaborada foi intitulada Bombeando vida: um coração criativo, em que a metáfora da função do coração de bombear sangue é comparada a experiências e aos sentimentos humanos. Este coração que pulsa e impulsiona a vida, oxigena, nutri, dá força, é importante para a sobrevivência humana, de sonhos, de vontades, assim como o é a criatividade. Um coração cheio de experiências e sentimentos que bombeia estímulos para o fazer criativo.

Para a elaboração dos planos de ensino, partiu-se do pressuposto de que a Arte pode ser ensinada e, em específico, a criatividade pode ser estimulada, sendo o professor o mediador desse processo. A aula teve como conteúdo a figura do coração, formas comuns (estereótipo) e a produção autoral. Os objetivos configuraram-se de modo a apresentar produções artísticas que tenham o coração como tema, a fim de que os alunos tenham repertório imagético para se desvincularem de formas comuns realizando trabalhos criativos.

Para tanto, no início da aula foi anunciado aos alunos que discutiríamos sobre um órgão que muitas vezes era designado a função de ser abrigo a todas as emoções: o coração. Na sequência, foi solicitado que cada aluno desenhasse um coração da 


\section{EDUCACÃO,}

ARTE'S E INCLUSÃO

Volume 18, n², AbriJun. 2020 I3ew 1304-9178

forma que quisesse, com os materiais que tínhamos em mãos: lápis grafite, lápis de cor, caneta e giz de cera (quadro 1). Deu-se continuidade a aula com a seguinte pergunta: o que o coração significa/representa para você? Algumas das respostas foram: "a parte pior do corpo é o coração, porque é a parte que mais dói, se eu pudesse, eu tiraria, pois sinto mais tristeza que alegria"; "sinto amor, paixão, alegria, felicidade. Ódio eu não sinto nem um pouco"; "alegria, emoção, felicidade e amizade"; "paixão, que dá até um arrepio no braço".

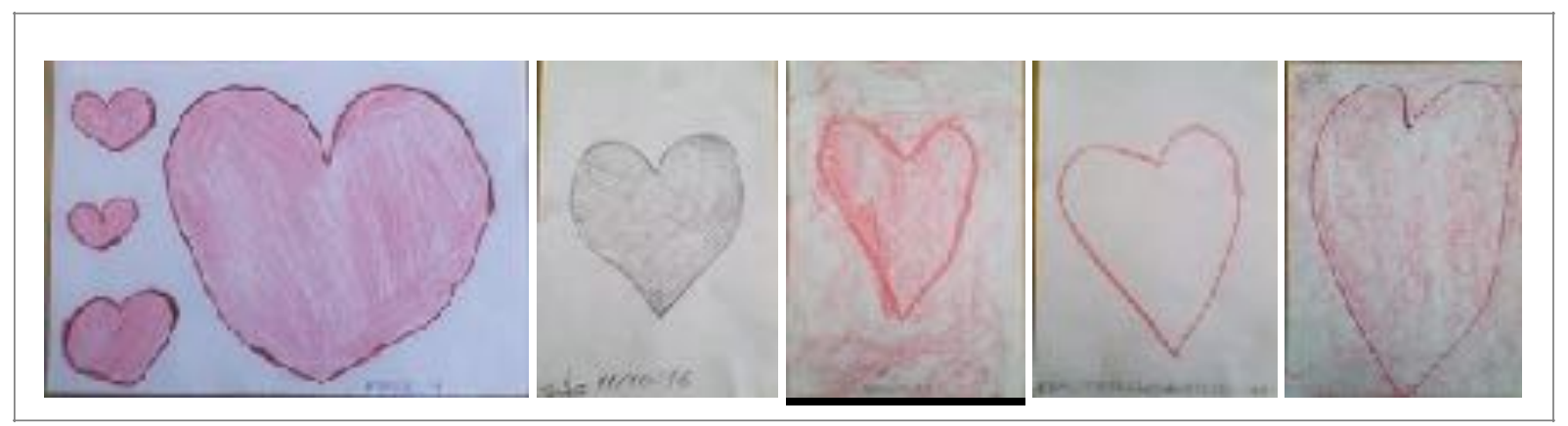

Quadro 1: Produções realizadas no início da aula sem mediação.

Fonte: arquivo da autora.

Após tal discussão, voltou-se para a apresentação dos slides, em que foram mostradas imagens de corações estereotipados, juntamente com as denominações de estereótipos, arquétipos e figuras comuns. Para a discussão em sala foi preferivel utilizar o nome figuras comuns para estereótipos. Concomitante às imagens estereotipadas dos corações, foi mostrado aos alunos os corações que eles próprios haviam desenhado momentos antes, com a intuição de que notassem como os desenhos de todos eles eram parecidos com os estereotipados presentes no slide. Logo em seguida, falou-se sobre o coração realista. Foi abordado a anatomia, o movimento do coração por meio de vídeo e sua função. Alguns alunos se mostraram com repulsa das imagens, associando com uma coxa de frango e uma linguiça. Outros diziam que todos temos coração e que ele fica na barriga.

Em seguida foram apresentadas várias obras de artistas que fizeram uso do tema coração, referências diversas, como pintura (bidimensional), escultura 
(tridimensional), arte digital e gravura (quadro 2). A leitura de cada imagem foi mediada por perguntas que estimulassem os alunos anotarem aspectos objetivos e subjetivos das obras, como por exemplo: de que material o coração da imagem era feito? Quais as cores utilizadas na produção? Em que ambiente a figura da imagem se encontra? Os objetos das imagens tinham relação entre si? O que entendíamos da imagem? Reflexão sobre o título quando a obra o tinha, entre outras perguntas específicas para cada produção.

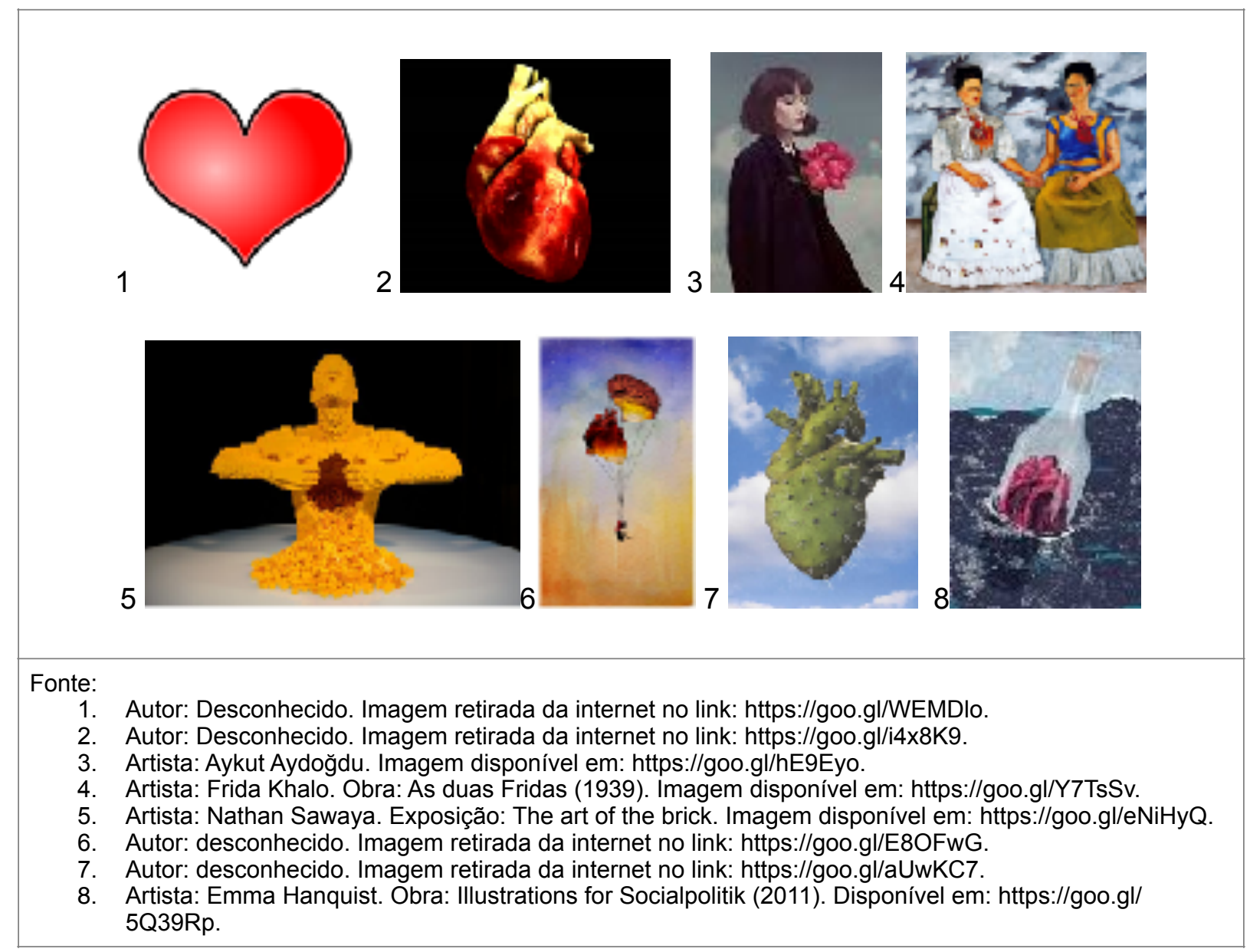

Quadro 2: algumas imagens utilizadas como referência para a aula com a temática coração.

Durante as leituras os alunos associavam com palavras ou coisas que tinham semelhança com a imagem em questão, como, por exemplo, uma das alunas começou a cantar a música "Coração espinhado" do cantor Emival Eterno Costa, conhecido 


\section{EDUCAÇÃO, \\ ARTES E INCLUSÃO}

como Leonardo, quando viu a imagem com um coração feito de cactos com espinhos. Entre tantas outras músicas que os alunos se recordaram ao ver imagens com coração, o que atesta que os alunos compreenderam a proposta da aula e estabeleceram associações com o seu repertório anterior de aprendizagem.

Por fim, a proposta artística tinha como objetivo que os alunos se desvinculassem da forma estereotipada do coração desenhada no início da aula, para dar vazão a produções autorais. Para tanto, os alunos tinham como referência as obras e imagens mediadas durante a aula, além de seu conhecimento pessoal. A obra Illustrations for Socialpolitik (2011) da artista Emma Hanquist, juntamente com as seguintes questões, constituiu a imagem de apoio para instigar as reinterpretações dos alunos: "Qual a mensagem que o seu coração quer passar? Do que o seu coração é feito? Qual é a sua forma? É grande ou pequeno? Está em qual local?". Os alunos puderam utilizar técnica mista, sendo disponibilizado lápis de cor, grafite, caneta, tinta aquarela e objetos variados. Segue as produções artísticas realizadas após a mediação docente e imagética (quadro 3). 


\section{EDUCAÇÃO, ARTES E INCLUSÃO}

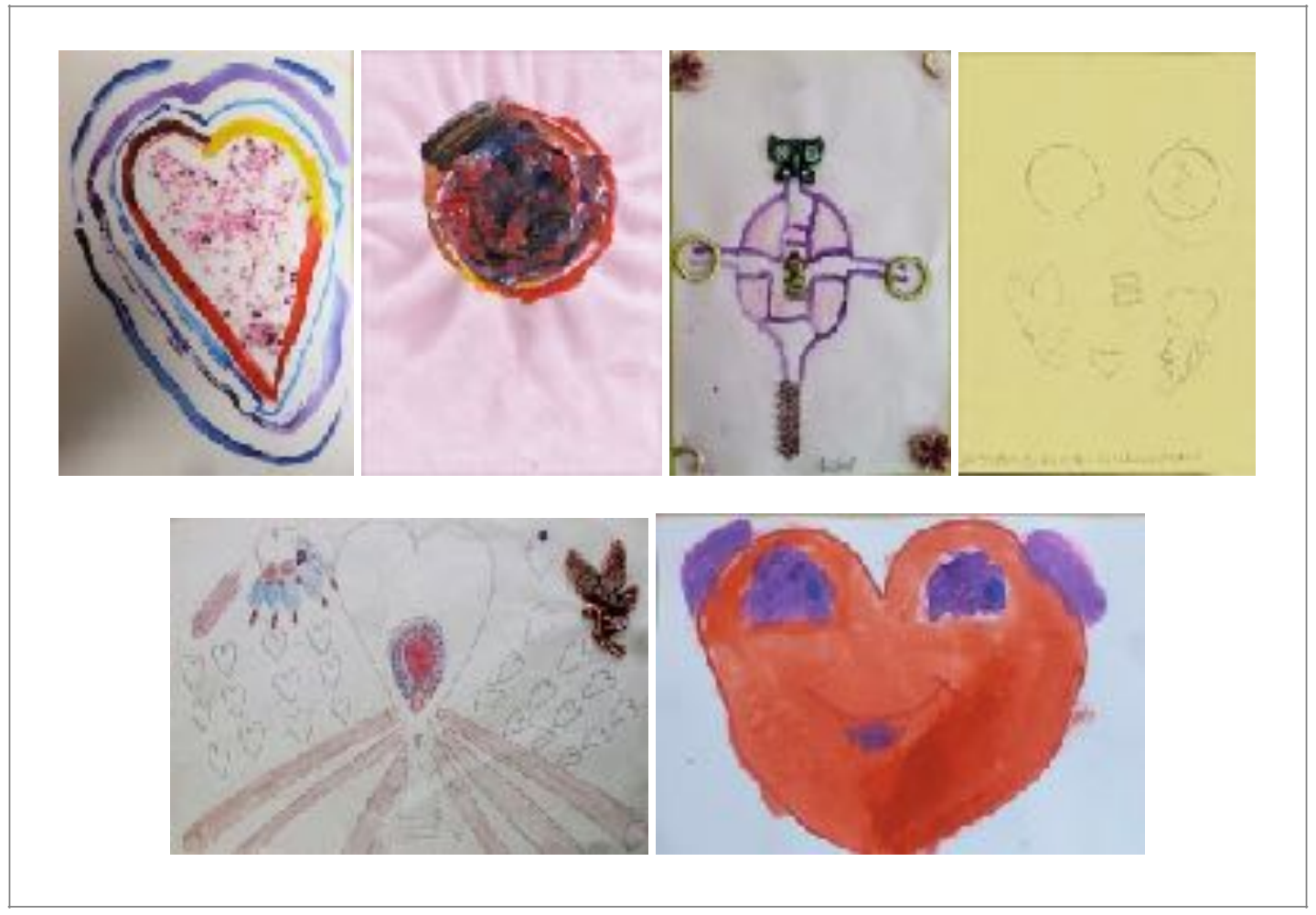

Quadro 3: Produções realizadas após a mediação das obras com temáticas de coração.

Fonte: arquivo da autora.

\section{ANÁLISE DAS PRODUÇÕES ARTÍSTICAS}

A compreensão que se tem das imagens se deu na percepção obtida durante o processo de criação, e também, por meio de comentários dos alunos conforme terminavam a atividade. Assim, pontua-se que além das interpretações apresentadas aqui, existem uma pluralidade de pontos de vista que podem vir a complementar ou divergir destas, pois, a leitura emerge de experiências individuais e coletivas que se faz de forma diferente em cada ser humano e a interpretação pode divergir em diferentes momentos.

Comparando as produções do quadro 1 , realizados no início da aula, com as do quadro 3 , produzidos após a mediação, pode-se observar como os desenhos ganharam outras cores além do vermelho, outras formas e dimensões, diferentes 
contextos e além de apresentar composições mais elaboradas, o que atesta que os estímulos trabalhados em aula foram apreendidos pelos alunos.

Vale ressaltar que, "[...] saber ler uma imagem é tão importante quanto produzir uma, porque ambas as atividades desenvolvem o processo criador e alimentam a consciência cultural" (BARBOSA, 2012, p. 69). Neste sentido, é importante destacar que houve aprendizado não somente no momento da pesquisa para o preparo das aulas e no momento de ministrá-las, mas também foi significativo o momento de analisar performance do professor durante as aulas, as interações dos alunos e principalmente as suas produções.

Como recorte para tal artigo, as análises a seguir são de produções de 2 alunos participantes. A produção 1 , do quadro 4 , mostra o desenho do coração estereotipado feito e preenchido com lápis grafite e, a produção 2 realizada após a mediação docente. Vê-se como a mediação se faz importante no processo de aprendizagem do aluno, pois após a mediação o aluno aventurou-se na criação de outras formas, sem ser a convencional, aqui entendida como esteriotipada, e criou um contexto para sua produção. Assim, notou-se que houve aprendizado e mudança no seu desempenho artístico, até porque tal aluno estava habituado a desenhar um coração partido e com as referências apresentadas ele expandiu sua criatividade.

Observando a produção 2 , do quadro 4 , tem-se um coração redondo contornado com canetinha roxa e com prolongamentos de supostas veias. Para a composição o aluno utilizou alguns objetos como 2 argolas douradas e uma borboleta nas extremidades do coração, nos cantos da folha colou flores e metades de uma argola. No centro da imagem colou uma menininha. Envergonhado, o aluno disse com a voz baixa que havia colocado a menina no centro do seu coração só para "zoar".

Em suma, durante as práticas e os diálogos sobre as emoções humanas, pudemos compreender que o aluno falava sempre sobre um coração partido e uma tristeza em seu coração. Sendo assim, notou-se que seus desenhos eram a exteriorização do que sentia na vida pessoal. Mesmo assim, após as aulas e as leituras de imagens, este aluno não se manteve no desenho do coração partido, além de criar 
uma outra forma para o coração, sem se ater ao estereótipo cortado ao meio. Ele colocou a figura de uma menina no centro, o que pode indicar a representação da pessoa que o partiu ou uma nova paixão. Um coração que, no prolongamento de suas veias, contêm duas argolas douradas, como alianças que selam um compromisso. $\mathrm{Na}$ extremidade superior do coração uma borboleta, que ao leve bater das asas sustenta um coração imenso, cheio de vontade e bondade. As metades das argolas podem representar a cisão de expectativas amorosas em sua vida e as flores remetem a delicadeza de uma mulher. Analisando a imagem, a composição também alude ao órgão feminino, em que as argolas compõem os ovários, o coração o útero e os strass rosa aludem a uma vagina. A menina é gerada pelo órgão. Uma paixão se formando. Outra leitura possível é do símbolo da cruz presente dentro do coração, em que a menina no centro é exaltada, glorificada, iluminada, como se fosse uma espécie de deusa. A simbologia da cruz nesta produção pode apresentar diversas interpretações se pensarmos que a cruz tem significados diferentes nas culturas e religiões.

Um coração imenso, que sofre por fazer outras pessoas passarem vergonha ao seu lado e por possíveis decepções amorosas, conforme o aluno explicitou em sala. Um coração que inventa, batalha, ajuda, compartilha e que, principalmente, alegra. Um coração que tem todas as portas abertas para acolher e amar o novo, um coração que pode aprender e criar. 


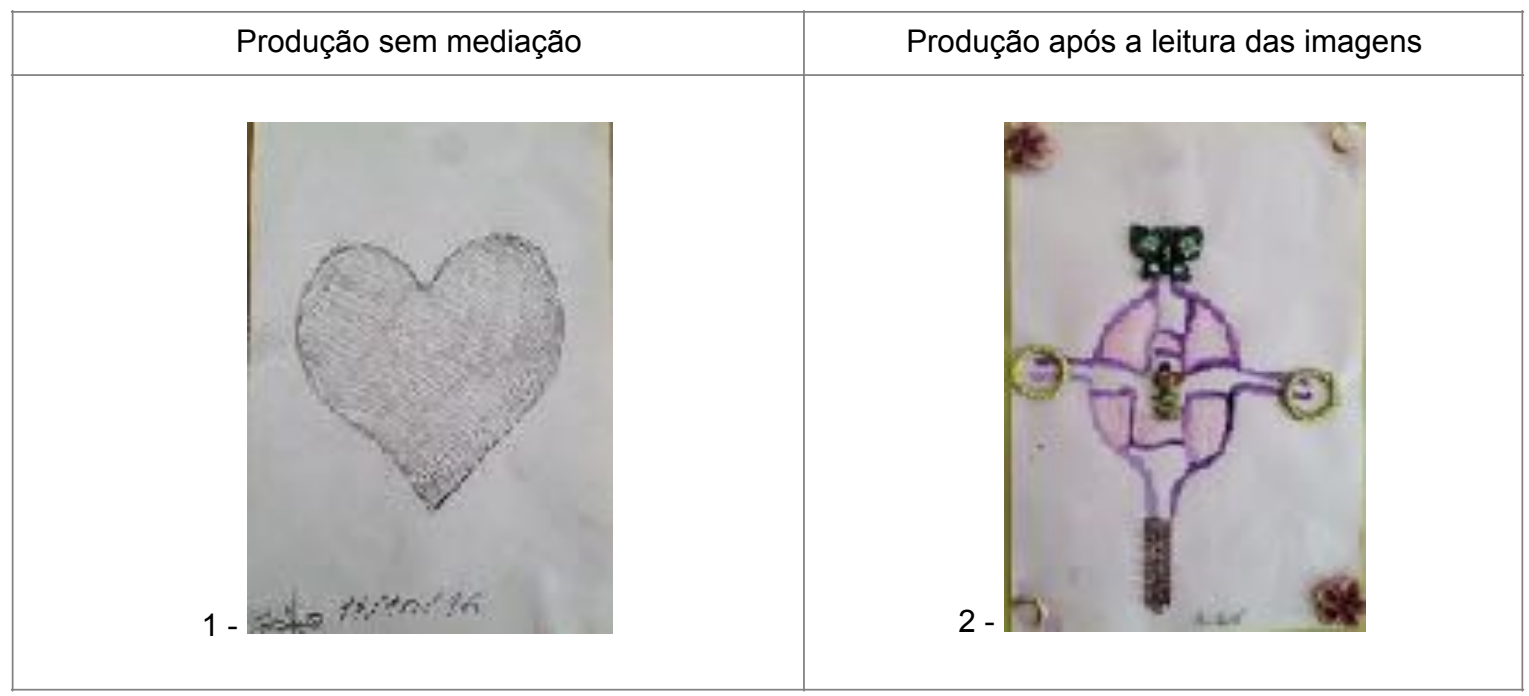

Quadro 4: Produções realizadas por um dos alunos nas aulas com o tema coração. Fonte: arquivo da autora.

O quadro 5 contêm produções realizadas por uma aluna. Na produção 1 do quadro 5 a aluna fez uso de todo espaço da folha para compor seu coração. Nota-se na produção 2 o desenvolvimento artístico da aluna após a mediação. Vê-se que ela criou uma analogia com o coração e o significado deste para ela, "casamento" e, principalmente, com a ideia que expôs de "coração que arde". Visualiza-se uma fogueira que tem um grande coração no lugar do fogo, com vários corações menores ao redor, podendo ser a chama ou fumaça dessa fogueira. Utilizou algumas bijuterias para compor o centro do coração. A aluna tomava as bijuterias como referência para seu trabalho, copiando a olho nu algumas e acrescentando elementos em outras. A utilização das bijouterias lembrou a possível relação de importância que a aluna expressou ter em aulas anteriores, de que em um relacionamento o parceiro tem que dar joias à amada. Na parte superior do desenho há uma menina com asas, que em nossa leitura pode ser a própria aluna voando em meio à fumaça que exala corações e amor. Ou a "rainha" do amor, que observa de longe a grande fogueira. Também remete ao arquétipo do cupido, um deus do amor. O cupido que com o ferimento causado pelas suas flechas despertava amor e paixão nas suas vítimas. 


\section{EDUCAÇÃO, \\ ARTE'S E INCLUSÃO}

Um coração que sobe em direção aos céus; um coração imenso que tem força para sustentar e levantar-se. Um coração que sonha, criativo, se interessa, apaixonado, carismático, educado. Um coração sempre disposto a aprender e ensinar com suas histórias e imaginação.

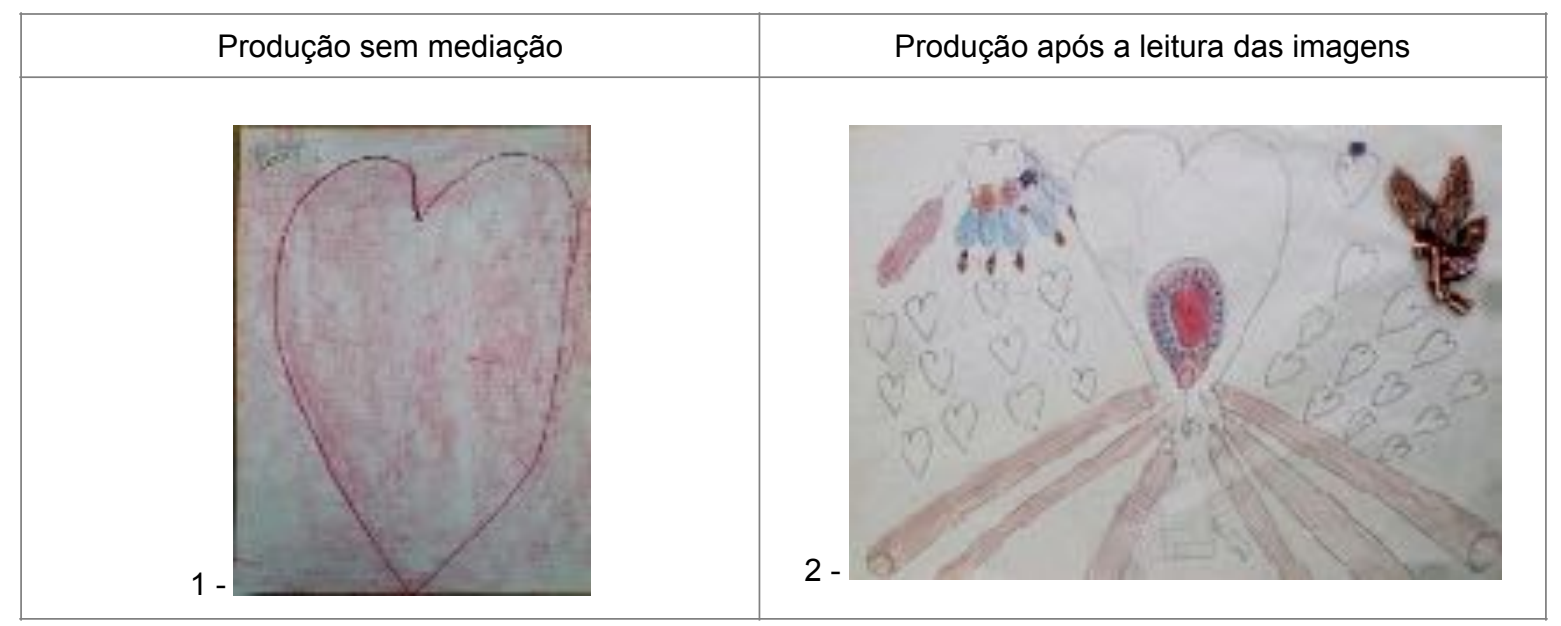

Quadro 5: Produções realizadas por uma aluna nas aulas com o tema coração.

Fonte: arquivo da autora.

\section{CONCLUSÃO}

No primeiro momento deste artigo procurou-se discutir conceitos que envolvem o ensino de arte/educação, a criatividade, estereótipo e a mediação docente a fim de compor o escopo teórico e metodológico para a elaboração das aulas de arte e das análises das produções artísticas.

Sendo assim, nota-se que a arte/educação tem como um de seus objetivos fomentar a expressão autoral, por meio do fazer artístico, utiliza-se da escuta ativa e de estratégias específicas para a demanda de cada aluno, a fim de alcançar a formação de pensamento crítico, inovador, criativo e humanizado. Estratégias estas pensadas pelo professor mediador, pois, entende-se que o modo como a mediação é conduzida representa a causa principal para o desenvolvimento do ensino e aprendizagem. 
Considera-se que educação inclusiva se faz eficaz quando há movimentação na escola, contando com professores profissionais na área, recursos pedagógicos e adaptação da estrutura escolar, que estejam interessados no desenvolvimento e aprendizagem significativa do aluno que apresenta necessidades especiais de ensino e, primeiramente, que o aluno se sinta bem em ser incluído em uma escola regular. A educação inclusiva luta para que o aluno tenha direito, acesso e permanência nas escolas regulares, com o intuito de que os preconceitos sejam eliminados e que o aluno com deficiência se sinta membro da sociedade da qual faz parte. Contudo, de certa forma, a inclusão apresenta um sistema excludente dentro do sistema capitalista, em que os indivíduos que não possuem condições de produção no mercado consumidor são marginalizados. Além disso, o aluno com deficiência tem o direito de frequentar o ensino regular, mas as condições ainda não são favoráveis à sua permanência e a uma educação significativa. Faz-se necessária a introdução de apoios, serviços e suportes nas escolas que necessitam de investimentos financeiros.

Em específico, tratando-se da realidade do grupo de pesquisa, foi analisada nas produções dos alunos a repetição de desenhos estereotipados, o que ocasionou a interrogação: como planejar aulas de arte para pessoas com deficiência intelectual que estimulem a criação e amplie o repertório artístico? Assim, por meio dos estudos sobre o estereótipo e a criatividade, foram elaboradas aulas com a temática "coração", a fim de que o conhecimento e criatividade fossem ampliados por meio da mediação docente. Após ter realizado a leitura das produções dos alunos, conclui-se que a mediação cultural foi agente importante para a ampliação do repertório artístico dos alunos, o que permitiu que eles vinculassem novos elementos aos desenhos estereotipados, dando lugar a um processo de criação artístico autoral. A mediação pressupõe diálogos com a cultura visual do aluno, do professor e de novas referências, sendo um agente na promoção social e cultural dos envolvidos. Com tais pressupostos aprendeu-se a olhar com mais atenção as experiências e os conteúdos que os alunos ofereciam e não apenas as experiências encontradas em livros, como notei que estava fazendo no início da pesquisa. Pois, vale destacar, que integrar os saberes para 
ampliá-los são processos que envolvem uma prática crítica e autocrítica. Também se destaca que a produção artística não acontece sem que existam condições materiais, psicológicas e experiências anteriores que favoreçam seu desenvolvimento.

As dificuldades encontradas na expressão autoral e a recorrência de desenhos estereotipados apresentaram-se semelhantes no ensino formal por alunos sem deficiência intelectual. Notou-se que a diferença de ensino para pessoas com deficiência intelectual e pessoas sem deficiência, estava na forma como o mesmo conteúdo deveria ser abordado, na utilização de recursos didáticos, no tempo de aula e na especificidade do aluno. Com essa linha de pensamento, vale trazer uma das questões abordadas na introdução deste artigo: as pessoas com deficiência intelectual estão aquém das consideradas normais no que diz respeito à criação artística?

Por fim, inferimos que a mediação docente, os recursos didáticos e os aspectos socioculturais constituem papel primordial no processo de aprendizagem, na socialização cultural e estímulo da criatividade de pessoas com deficiência intelectual. Por meio das análises realizadas, conclui-se que as produções autorais expressaram autonomia frente a formas visuais e a personalidade de cada aluno, contribuindo para a construção da identidade como indivíduo e como grupo.

\section{REFERÊNCIAS:}

ACHINTE, Adolfo Albán. La comunalidad creativa una pedagogía de la imagen. In: CATELAN, Fernando Bueno; LOPES, Valter Frank de Mesquita. (orgs). Nortes da Resistência: Lugares e Contextos da Arte Educação no Brasil: Anais [do] XXIX Congresso Nacional da Federação de Arte/Educadores do Brasil [e] VII Congresso Internacional dos Arte/Educadores. Manaus, AM, 2019. ISSN: 2525-880X. p.23-43.

ALENCAR, E. M. L. S; FLEITH, D. S. Contribuições teóricas recentes ao estudo da criatividade. Psic.: Teor. E Pesq., Brasília, Vol. 19, n. 1, p. 1-8, Jan-Abr 2003. ISSN 0102-3772. Disponível em: < http://www.scielo.br/pdf/ptp/v19n1/a02v19n1.pdf>. Acesso em: 09 jan. 2020.

AMABILE, Teresa e KRAMER, Steven. The progress principle, Using small wints to ignite joy, engagement and creativity and work. Havard Business Review Press, 2011.

. O princípio do progresso. Rocco, 2013. 
ARRIAGA, Imanol Aguirre. Ana Mae Barbosa: ou como navegar entre a fidelidade a um ideário e a "incessante busca de mudança". In: BARBOSA, Ana Mae. A imagem no ensino da Arte: anos 1980 e novos tempos. São Paulo: Perspectiva, 2014, p.11-24.

AZEVEDO, Fernando Antônio Gonçalves. A arte possibilita ao ser humano repensar suas certezas e reinventar seu cotidiano. In: BARBOSA, Ana Mae; COUTINHO, Rejane Galvão (Orgs.). Arte/educação como mediação cultural e social. São Paulo: UNESP, 2009, p. 334-343.

BARBOSA, Ana Amália Tavares. Além do corpo: uma experiência em Arte/Educação. Tese: Universidade de São Paulo, 2012.

BARBOSA, Ana Mae. A imagem no ensino da Arte: anos 1980 e novos tempos. São Paulo: Perspectiva, 2014.

Ensino da Arte: memória e história. São Paulo: Perspectiva, 2008.

Inquietações e mudanças no ensino da arte. São Paulo: Cortez, 2011.

CABRERA SALORT, Ramón. Saber olhar com olhos próprios (Uma escola necessária para evitar ideias fora de lugar). Revista GEARTE, [S.I.], v. 6, n. 2, jul. 2019. ISSN 2357-9854. Disponível em: <https://seer.ufrgs.br/gearte/article/view/92912>. Acesso em: 10 out. 2019. doi:https://doi.org/10.22456/2357-9854.92912.

COUTINHO, Rejane Galvão. Estratégias de mediação e a abordagem triangular. In: BARBOSA, Ana Mae; COUTINHO, Rejane Galvão (Orgs.). Arteleducação como mediação cultural e social. São Paulo: UNESP, 2009, p 171-186.

CSIKSZENTMIHALYI, M. Creativity. New York: HarperCollins, 1996.

FLUIR (FLOW) Una Psicologia de la felicidad. Barcelona: Kairós, 2013.

FERRAZ, Maria Heloísa C. de T; FUSARI, Maria F. de Rezende. Metodologia do Ensino da Arte: fundamentos e proposições. São Paulo: Cortez, 2009.

GARCIA, Dorcely Isabel Bellanda. Aprendizagem e desenvolvimento das funções complexas do pensamento e a deficiência intelectual na perspectiva histórico-cultural. In: SHIMAZAKI, Elsa Midori; PACHECO, Edilson Roberto (org). Deficiência e inclusão escolar. Maringá: Eduem, 2012, p. 97-113.

KON, Victor. Educación por el Arte vs. Colonización de la Subjetividad. Revista GEARTE, [S.I.], v. 6, n. 2, jul. 2019. ISSN 2357-9854. Disponível em: <https://seer.ufrgs.br/gearte/article/view/ 92914 >. Acesso em: 10 out. 2019. doi:https://doi.org/10.22456/2357-9854.92914.

LIPOVETSKY, Giles; SERROY, Jean. A estetização do mundo: o viver na era do capitalismo artista. São Paulo: Companhia das Letras, 2015.

LOPONTE, Luciana Gruppelli. Pedagogias visuais do feminino: arte, imagens e docência. Currículo Sem Fronteiras, Porto Alegre, v. 8, n. 2, p.148-164, jul/dez 2008. 
LUBART, Todd. Psicologia da Criatividade. Porto Alegre: Artmed, 2007.

\& STERNBERG, R.J.(1995). An investment approach to creativity. In: S.M, Smith, T.B. Ward \& R.A. Finke (eds.). The creative cognition approach. Cambridge (MA), MIT Press.

MERLIN, Nora. Colonização da subjetividade e neoliberalismo. Revista GEARTE, [S.I.], v. 6, n. 2, jul. 2019. ISSN 2357-9854. Disponível em: <https://seer.ufrgs.br/gearte/article/view/92906>. Acesso em: 10 out. 2019. doi: https://doi.org/10.22456/2357-9854.92906.

MERLIN, Nora. Mentir y colonizar: obediencia inconsciente en la subjetividad neoliberal. Buenos Aires: Letra Viva, 2019. NING, Luo. The International Journal of Arts Education, Volume 17, Número 2, dezembro de 2019, p. 83-95. ISSN 1728-175X, National Taiwan Arts Education Center.

RAPAILLE, Clotaire. 0 código cultural: por que somos tão diferentes na forma de viver, comprar e amar. Rio de Janeiro: Elzevir Editora Ltda, 2007.

REILY, Lucia. O ensino de artes visuais na escola no contexto da inclusão. Cad. Cedes, Campinas, vol. 30, n. 80, p. 84-102, jan.-abr. 2010. Disponível em: <http:// www.cedes.unicamp.br/>. Acesso em: 10 jan. 2017.

SHIMAZAKI; Elsa Midori; MORI, Nerli Nonato Ribeiro. Atendimento educacional especializado à pessoa com deficiência intelectual. In: SHIMAZAKI, Elsa Midori; PACHECO, Edilson Roberto (org). Deficiência e inclusão escolar. Maringá: Eduem, 2012.

SOUZA, Vanessa Raquel Lambert de. A sobrevivência das imagens: Escultura e marcas gráficas na arte afro-brasileira. Tese de doutorado. UNESP. 2017.

TOURINHO, Irene. Visualidades comuns, mediação e experiência cotidiana. In: BARBOSA, Ana Mae; COUTINHO, Rejane Galvão (Orgs.). Arte/educação como mediação cultural e social. São Paulo: UNESP, 2009. p 268-284.

VIANNA, Maria Letícia Rauen. Desenhando com todos os lados do cérebro. Curitiba: Ibpex, 2010.

VIGOTSKI, Lev Semyonovich. Imaginação e Criação na Infância. São Paulo: Ática, 2009.

ZORZAL, M. F.; BASSO, I. S. Por uma ontologia da criatividade: uma abordagem históricocultural. In: $25^{a}$ Reunião anual da Associação Nacional de Pós-Graduação e Pesquisa em Educação, 2002, Caxambu. 